\title{
Análise das córneas do Banco de Olhos da Santa Casa de São Paulo utilizadas em transplantes
}

\author{
Analysis of the transplanted corneas at Santa Casa de São Paulo Eye Bank
}

Ronaldo Yuiti Sano ${ }^{1}$

Fabiana Tiemi Sano ${ }^{2}$

Maria Cristina Nishiwaki Dantas ${ }^{3}$

Aline Cristina Fioravanti Lui ${ }^{4}$

Milena Eimi Sano ${ }^{5}$

Adamo Lui Neto ${ }^{6}$

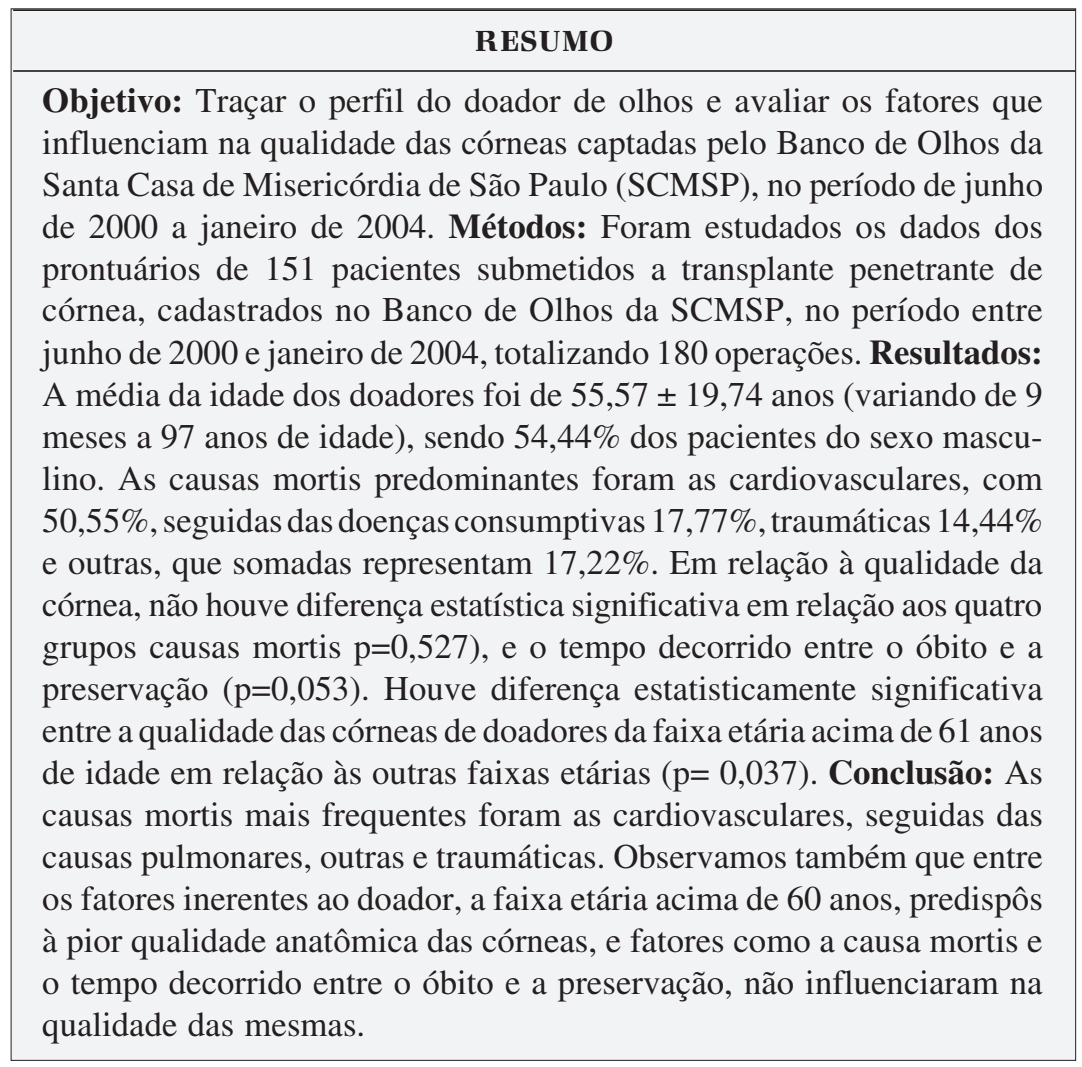

Descritores: Transplante de córnea; Doadores de tecidos; Preservação de tecido; Banco de olhos

\footnotetext{
Trabalho realizado na Santa Casa de Misericórdia de São Paulo - SCMSP - São Paulo (SP) - Brasil.

${ }^{1}$ Assistente da Seção de Retina da Santa Casa de Misericórdia de São Paulo - SCMSP - São Paulo (SP) - Brasil.

${ }^{2}$ Estagiária da Seção de Lentes de Contato e Cirurgia Refrativa da SCMSP - São Paulo (SP) - Brasil.

${ }^{3}$ Professora Adjunta e Diretora do Serviço de Oftalmologia da SCMSP - São Paulo (SP) - Brasil.

${ }^{4}$ Estagiária da Seção de Retina da SCMSP - São Paulo (SP) - Brasil.

${ }^{5}$ Residente da Universidade de São Paulo - USP - São Paulo (SP) - Brasil.

${ }^{6}$ Doutor, Professor Assistente, Chefe do Banco de Olhos da SCMSP - São Paulo (SP) - Brasil.

Endereço para correspondência: Ronaldo Yuiti Sano Av. Mofarrej, 154 - Apto. 201 - Bloco 01 - São Paulo (SP) CEP 05311-000

E-mail: rysano@hotmail.com

Recebido para publicação em 30.07.2008

Última versão recebida em 02.04 .2010

Aprovação em 04.05.2010
}

\section{INTRODUÇÃOO}

A Associação Brasileira de Transplante de Órgãos estima que em 2007 foram realizados 9.940 transplantes de córnea no Brasil ${ }^{(1)}$. É notório o aumento do número de transplantes de córnea realizados na última década, sendo que alguns fatores têm grande influência nesta evolução. Melhora tecnológica do instrumental de microcirurgia, aprimoramento dos meios de preservação, melhor controle médico no período pós-operatório (descoberta de drogas anti-inflamatórias e imunossupressoras), além do melhor entendimento da fisiologia da superfície corneal permitiram a obtenção de resultados progressivamente melhores de transplante de córnea, tornandose uma das cirurgias oculares mais realizadas em todo o mundo ${ }^{(2-6)}$. Outro fator responsável pelo crescente número de transplantes de córnea é a melhor organização do trabalho realizado pelos Bancos de Olhos em que 
rápidas notificação e preservação, possibilitam melhor condição anatômica da córnea doadora ${ }^{(7-8)}$.

A boa qualidade da córnea doada e a adequada manutenção desta até sua utilização são de suma importância para um bom prognóstico visual final. Existem fatores que influenciam na qualidade da córnea doada, dentre todos, destaca-se a idade do doador, a causa mortis do doador e o tempo de permanência da córnea doada nos meios de preservação ${ }^{(9-11)}$.

A idade avançada do doador é um fator que pode influenciar negativamente na qualidade da córnea captada ${ }^{(11)}$. Quanto maior a idade do doador, pior é a condição anatômica corneal deste paciente, embora existam estudos que contestam este fato $^{(9,12-13)}$. O "Cornea Donor Study" demonstrou que a córnea não deve ser considerada inadequada para transplante quando considerada apenas pela avançada idade do doador, mas deve-se levar em conta a sua qualidade tecidual e contagem endotelial $^{(14)}$.

A causa mortis também pode influenciar na qualidade da córnea doada. Pacientes vítimas de doenças consumptivas apresentam pior qualidade corneal. Já pacientes que tiveram uma morte repentina, apresentaram qualidade anatômica corneal melhor se comparada com aqueles ${ }^{(9,12-13)}$.

A permanência da córnea por tempo prolongado nos meios de preservação pode estar associada a sua pior qualidade e maior índice de falência primária ${ }^{(10,13,15-16)}$. Mesmo após a criação de meios que possibilitam a preservação das córneas por até 14 dias, estudos experimentais e clínicos mostraram maior perda endotelial e falência primária quando se excede o período de sete dias ${ }^{(16-17)}$.

Este estudo tem como objetivos traçar o perfil do doador de córnea e verificar se os fatores acima citados apresentaram relação significativa na qualidade anatômica das córneas captadas pelo Banco de Olhos da Santa Casa de Misericórdia de São Paulo.

\section{MÉTODOS}

Foram estudados os dados dos prontuários de 151 pacientes submetidos a transplante penetrante de córnea, cadastrados no Banco de Olhos da SCMSP, no período entre junho de 2000 e janeiro de 2004, totalizando 180 cirurgias.

Foram avaliados dados referentes aos doadores de córnea: idade, sexo e causa mortis.

A causa mortis considerada foi a registrada no atestado de óbito do doador. Para comparação com a literatura, as causas mortis foram divididas em quatro grupos: doenças consumptivas, doenças cardiovasculares, traumatismos e outros.

- Doenças consumptivas (câncer, septicemia, broncopneumonia e insuficiência hepática).

- Doenças cardiovasculares (acidentes vasculares cerebrais, aneurismas de aorta roto, aneurisma cerebral e tromboembolismo pulmonar).

- Traumatismos (ferimento por arma de fogo, ferimento por arma branca, traumatismo cranioencefálico e acidente automobilístico).
- Outros (outra doença que causou a morte que não se encontra em nenhuma dos grupos anteriores $-1^{\circ}, 2^{\circ}$ ou $3^{\circ}$ ).

A sistemática do Banco de Olhos foi avaliada através da qualidade das córneas captadas e preservadas, tempo decorrido entre a morte do doador e a preservação de suas córneas e tempo decorrido entre o início da preservação das córneas e a sua utilização.

As córneas doadas foram avaliadas mediante biomicroscopia por dois médicos da Seção de Córnea e Doenças Externas, no dia da preservação e no dia do transplante, seguindo os critérios propostos pela Associação Panamericana de Banco de Olhos (APABO). Avaliou-se a integridade do epitélio, halo senil, edema estromal, dobras de Descemet e a presença de "guttata". Para cada um desses itens foram dadas as seguintes notas: 0 (excelente), 1 (boa), 2 (razoável) e 3 (ruim). A nota final atribuída à córnea foi a que mais se repetiu nos itens avaliados anteriormente. Por exemplo, se a maioria dos itens avaliados de uma córnea obteve nota 2 , esta foi considerada razoável.

Neste estudo, o meio de preservação utilizado em todos os casos foi o Optsol GS ${ }^{\circledR}$. Em todas as cirurgias foi realizado o transplante penetrante de córnea.

Todas as córneas foram disponibilizadas pela Central Estadual de Transplantes, seguindo fila única de inscrição. Portanto, as córneas utilizadas neste estudo foram provenientes de diferentes Bancos de Olhos.

Foi adotado o nível de significância de 5\% $(0,050)$ para aplicação dos testes estatísticos. Os testes utilizados foram Mann-Whitney, análise de variância e Kruskal-Wallis.

\section{RESULTADOS}

No período entre junho de 2000 e janeiro de 2004, foram realizados 180 transplantes penetrantes de córnea na Clínica Oftalmológica da Santa Casa de Misericórdia de São Paulo. Quanto aos doadores, a média da idade foi de 55,57 $\pm 19,74$ anos (variando de 9 meses a 97 anos de idade). Quanto ao sexo, $98(54,44 \%)$ eram do sexo masculino e $82(45,55 \%)$ do sexo feminino.

A tabela 1 mostra a comparação entre a qualidade da córnea doada e a idade do doador.

Houve diferença estatisticamente significante entre a qualidade das córneas dos doadores acima de 61 anos de idade em relação às outras faixas etárias $(\mathrm{p}=0,037)$.

As causas mortis predominantes foram, cardiovasculares $50,55 \%$, seguidas das doenças consumptivas $17,77 \%$, traumáticas $14,44 \%$ e outras, que somadas representam 17,22\%.

A tabela 2 mostra o resultado da comparação entre as causas mortis e a qualidade da córnea doada.

Não houve diferença estatisticamente significante em relação aos quatro grupos de causas de morte, quanto à qualidade das córneas $(\mathrm{p}=0,527)$.

O tempo médio entre óbito do doador e preservação da córnea para os transplantes tectônicos foi de 448,8 $\pm 307,5$ minutos (variando de 45 a 1.540 minutos). 
Tabela 1. Comparação entre qualidade das córneas doadas e as faixas etárias de seus doadores, no período de junho de 2000 a janeiro de 2004

\begin{tabular}{|c|c|c|c|c|}
\hline \multirow[b]{2}{*}{ Idade } & \multicolumn{4}{|c|}{ Qualidade da córnea } \\
\hline & Excelente & Boa & Razoável & Ruim \\
\hline $0-20$ anos & $1(0,5)$ & $5(2,7)$ & $2(1,1)$ & $4(2,2)$ \\
\hline $21-40$ anos & $7(3,8)$ & $8(4,4)$ & $1(0,5)$ & $9(5,0)$ \\
\hline $41-60$ anos & $7(3,8)$ & $20(11,1)$ & $11(6,1)$ & $30(16,6)$ \\
\hline$>61$ anos & $2(1,1)$ & $18(10,0)$ & $12(6,6)$ & $43(23,8)$ \\
\hline Total & $17(9,4)$ & $51(28,3)$ & $26(14,4)$ & $86(47,7)$ \\
\hline
\end{tabular}

\begin{tabular}{|c|c|c|c|}
\hline \multirow[b]{2}{*}{ Qualidade da córnea } & \multicolumn{3}{|c|}{ Causa mortis } \\
\hline & Traumatismo & Doença cardiovascular & Doença consumptiva \\
\hline Excelente & $4(15,38)$ & $9(9,89)$ & $1(3,12)$ \\
\hline Boa & $9(34,61)$ & $27(29,67)$ & $5(15,62)$ \\
\hline Razoável & $4(15,38)$ & $12(13,18)$ & $7(21,87)$ \\
\hline Ruim & $9(34,61)$ & $43(47,25)$ & $19(59,37)$ \\
\hline Total & $26(100,00)$ & $91(100,00)$ & $32(100,00)$ \\
\hline \multicolumn{4}{|c|}{ Valores expressos em número (\%) } \\
\hline
\end{tabular}

Entre os transplantes ópticos, o tempo médio decorrido entre o óbito e o ato da preservação corneal foi de $396,1 \pm$ 288,6 minutos (variando de 40 a 960 minutos), sendo que $53 \%$ foram preservadas antes de 360 minutos após o óbito.

A tabela 3 mostra o resultado da comparação entre a média de tempo decorrido, entre o óbito e a preservação (transplantes ópticos e tectônicos), e qualidade das córneas doadas.

Em relação à qualidade da córnea, não houve uma diferença estatística significante do tempo decorrido entre o óbito e a preservação $(\mathrm{p}=0,053)$.

O tempo médio entre o ato de preservação e a realização do transplante foi de 15,2 \pm 14,3 dias (variando de 1 a 240 dias) para os transplantes tectônicos e 6,5 $\pm 5,4$ dias (variando de 1 a 13 dias) para os transplantes ópticos. Entre esses, $71 \%$ das córneas foram transplantadas antes de sete dias da preservação.

A avaliação da córnea para os transplantes tectônicos foi: "ruim" para 83 córneas captadas $(72,17 \%)$, "razoável” para 13 córneas $(11,30 \%)$ e "boa" para 9 córneas avaliadas $(7,82 \%)$, estas últimas consideradas córneas ópticas priorizadas.

Dos transplantes com finalidades ópticas observamos que 41 foram realizados com tecidos avaliados como de qualidade "boa" (54,66\%), 17 considerados "excelentes" $(22,66 \%)$ e 17 com córneas consideradas como razoáveis.

\section{DISCUSSÃO}

Apesar de a avaliação biomicroscópica contar com parâmetros subjetivos, no presente estudo, os doadores com mais de 61 anos apresentaram alterações anatômicas das córneas que comprometeram a sua qualidade $(23,8 \%)$. A quantidade de córneas ruins nessa faixa etária em relação aos outros grupos etários foi significante $(\mathrm{p}<0,037)$.

Com o avançar da idade, verifica-se progressiva redução do número de células endoteliais, ocorrendo polimegatismo e polimorfismo das células remanescentes na tentativa de preenchimento dos espaços deixados sem cobertura ${ }^{(8-9,18)}$. Muitos cirurgiões preferem utilizar córneas de doadores com idade inferior a 60 anos, por acreditarem que a utilização de córneas com maior população endotelial estaria relacionada à maior transparência do enxerto no período pós-operatório. Não há trabalhos na literatura que tenham comprovado a menor eficácia, ou piores resultados finais dos transplantes efetuados com córneas de doadores com mais de $60 \operatorname{anos}^{(11,19)}$. O "Cornea Donor Study" (CDS) ${ }^{12}$, contribuiu para esclarecer algumas destas dúvidas. Segundo esse grande estudo multicêntrico a sobrevida (em 5 anos) dos enxertos realizados com tecidos de doadores de 66 anos ou mais foi a mesma dos enxertos realizados com tecidos de doadores mais jovens, de até 66 anos, considerando os resultados para transplante de risco moderado. A maioria das córneas procedentes de doadores idosos costuma ser classificada biomicroscopicamente como de pior qualidade, como visto neste estudo. Por outro lado, córnea de doadores idosos, classificadas como de boa qualidade, se transplantadas, apresentam resultados semelhantes às córneas de doadores jovens ${ }^{(14)}$.

Deve-se lembrar que o doador jovem, não confere qualidade absoluta ao tecido corneal somente pela sua idade. Observamos que treze córneas de pacientes entre 0 e 40 anos foram consideradas "ruins" (Tabela 1). Não se pode descartar 
Tabela 3. Comparação entre média de tempo decorrido entre óbito e preservação e qualidade da córnea doada

\begin{tabular}{lcc} 
& & \multicolumn{2}{c}{ Qualidade da córnea } & \multicolumn{1}{c}{ Búdia de tempo (minutos) } & Excelente & Bazoável & Ruim & 388,51 & 370,54 \\
Entre óbito e preservação & 283,75 & 454,27 \\
Fonte: Departamento de Oftalmologia da SCMSP de junho de 2000 a janeiro de 2004 &
\end{tabular}

a possibilidade do comprometimento dessas córneas durante o período de internação hospitalar (cuidados inadequados na unidade de terapia intensiva), ou no período entre a morte e a captação. Diante dessa possibilidade, a manutenção de cuidados oculares como lubrificação dos olhos durante o período de internação hospitalar e o fechamento das pálpebras após o óbito dos pacientes são de fundamental importância para preservar a boa qualidade das córneas ${ }^{(20)}$.

Outra possibilidade é que tenha ocorrido utilização de técnica inadequada na sua preservação. Portanto, o treinamento de médicos ou técnicos para captação e preservação adequadas é de grande valia na tentativa de não comprometer a qualidade das córneas potencialmente destinadas ao transplante óptico.

A causa mortis é um fator que influencia no metabolismo e na integridade endotelial da córnea. Estudos mostraram que o traumatismo como causa de óbito predispõe a maior perda endotelial durante a cultura de tecido corneal ${ }^{(9,12,21)}$. Neste estudo, o traumatismo ocupou a terceira causa mais frequente de morte dos doadores. Não houve diferença estatisticamente significante em relação aos quatro grupos de causas de morte, quanto à qualidade das córneas. Assim, contrariando o estudo de Sobottka et al. ${ }^{(9)}$, as córneas de pacientes que tiveram o trauma como causa mortis não apresentaram diferenças em relação às córneas de paciente que faleceram de causa não traumática.

Redbrake et al. ${ }^{(12)}$ demonstraram em seus estudos clínicos que doadores falecidos de maneira repentina, como infarto fulminante, apresentaram melhor metabolismo das células corneais do que doadores que faleceram de doenças consumptivas. Segundo os autores, doenças que comprometem o metabolismo celular sistêmico também comprometem o metabolismo corneal, piorando a qualidade dessas córneas para o transplante ${ }^{(12)}$

Neste estudo, os óbitos devidos às doenças cardiovasculares, ocuparam a primeira causa de morte. Observou-se que $81,24 \%$ das córneas de doadores que faleceram de doenças consumptivas e $60,43 \%$ das córneas de doadores que faleceram de doenças cardiovasculares foram classificadas como "razoáveis" ou "ruins". Não houve diferença estatisticamente significante entre esses dois grupos, mostrando que córneas de pacientes falecidos por doenças consumptivas não apresentaram pior qualidade em relação às córneas de pacientes que faleceram repentinamente.

A eficiência de um Banco de Olhos pode ser indiretamente avaliada pelo tempo decorrido entre óbito e preservação dos tecidos. Somente $53 \%$ das córneas destinadas para o transplante óptico foram preservadas antes de 360 minutos, tempo preconizado pela APABO e por Van Meter et al. ${ }^{(21)}$, que é de 360 minutos. O maior tempo decorrido entre óbito e preservação pode levar à perda endotelial e consequente piora da qualidade da córnea, contribuindo para maior risco para falência primária do transplante ${ }^{(22)}$.

Já os tecidos destinados aos transplantes tectônicos, tiveram como tempo médio decorrido entre o óbito e a preservação aproximadamente 7 horas e meia. Como se pode observar, no caso dos transplantes tectônicos, o tempo utilizado para a preparação da córnea e sua utilização respeitou o preconizado ${ }^{(23)}$.

Com o treinamento da equipe de captação e preservação, composta por técnicos responsáveis exclusivamente pelo processo da entrevista familiar, captação e preservação de córneas, esperamos que o tempo entre o óbito e a preservação seja reduzido, além de proporcionar melhor técnica de preservação das córneas e consequente melhora de suas qualidades. Este processo já está sendo implantado em nosso Serviço.

No nosso estudo, o tempo médio de permanência da córnea doada em meio de preservação aproximou-se de 7 dias. Embora, $54(71 \%)$ das córneas foram utilizadas até 7 dias da preservação e aproximadamente 22 córneas (29\%) não foram utilizadas antes desse período. Assim, deve-se diminuir o tempo entre preservação e utilização das córneas para transplante óptico.

Diferentemente da idade do doador acima de 60 anos, que nesta série esteve relacionada à pior qualidade anatômica das córneas segundo classificação morfológica, observamos que o tempo decorrido entre o óbito e a preservação, assim como a causa mortis não influenciaram na qualidade das mesmas.

O estudo da qualidade tecidual da córnea, no que tange à morfologia do mosaico endotelial, pode ser auxiliado pelo exame de microscopia especular para banco de olhos. A sua contribuição é inegável e seria um dado importante para este estudo. No entanto, na grande maioria dos bancos de olhos brasileiros e em outros bancos de olhos em todo o mundo este exame não está disponível e sua utilização não é corriqueira. Assim, na avaliação da qualidade da córnea sem a utilização da microscopia especular a observação rigorosa e a utilização dos recursos da lâmpada de fenda têm extrema importância e grande valia. Entretanto, há que se lembrar que os parâmetros morfológicos não asseguram a qualidade funcional do tecido após a cirurgia.

Observou-se neste estudo que 9 córneas avaliadas como "boas" foram utilizadas para transplante tectônico (córnea óptica priorizada). Transplante tectônico utilizando-se córnea de boa qualidade é indicado em raros casos, como em 
crianças abaixo de 7 anos com opacidade de córnea bilate$\mathrm{ral}^{(24)}$, na tentativa de evitar ambliopia.

Devemos salientar que a preservação dos tecidos para enxerto óptico além do tempo preconizado não é desejável, pois pode contribuir para pior "performance" do transplante. Na Instituição, esforços têm sido feitos para melhorarem esse aspecto e estudos futuros poderão vir a mostrar a superação deste problema.

\section{ABSTRAC}

Purpose: To identify the donors' profile and evaluate the factors influencing the quality of the donated corneas in Santa Casa Eye Bank, from July, 2000 to January, 2004. Methods: Data from the charts of 151 patients submitted to penetrating keratoplasty, registered in Santa Casa Eye Bank, from July, 2000 to January 2004 resulted in 180 surgeries. Results: Mean age of the donors was $57.57 \pm 19.74$ years old (varied from 9 months to 97 years old) and $54.44 \%$ were male. The cause of death was predominantly cardiovascular $(50.55 \%)$, followed by consumptive diseases $(17.77 \%)$, trauma (14.44\%) and others $(17.22 \%)$. Considering the quality of the cornea, there was no statistically significant difference among the three main groups of cause of death $(\mathrm{p}=0.527)$ and time from death to corneal preservation $(\mathrm{p}=0.053)$. There was a statistically significant difference between quality of donated corneas above 61 years old and other ages $(\mathrm{p}=0.037)$. Conclusion: The most frequent cause of death was cardiovascular, followed by pulmonary diseases and trauma. We could also note that factors inherent to donor like age ( $>60$ years old) predisposed to a worse anatomical quality of the cornea and factors like cause of death and time between death and preservation did not influence the quality of the cornea.

Keywords: Corneal transplantation; Tissue donors; Tissue preservation; Eye banks

\section{REFERÊNCIAS}

1. Associação Brasileira de Transplante de Órgãos. Estatística de transplante [Internet]. São Paulo: ABTO; s.d. [citado 2010 Abr 02]. Disponível em: http:// www.abto.org.br/abtov02/portugues/populacao/transplante/estati.aspx? idCategoria $=5$

2. Cattani S, Kwitko S, Kroeff MAH, Marinho D, Rymer S, Bocaccio FL. Indicações de transplante de córnea no Hospital de Clínicas de Porto Alegre. Arq Bras Oftalmol. 2002;65(1):95-8.

3. Endriss D, Cunha F, Ribeiro MP, Toscano J. Ceratoplastias penetrantes realizadas na Fundação Altino Ventura: revisão dos resultados e complicações. Arq Bras Oftalmol. 2003;66(3):273-7.
4. Fabris C, Correa ZMS, Marcon AS, Castro TN, Marcon IM, Pawlowski C. Estudo retrospectivo dos transplantes penetrantes de córnea da Santa Casa de Porto Alegre. Arq Bras Oftalmol. 2001;64(5):449-53.

5. Kamp TM, Fink NE, Enger C, Maguire MG, Stark WJ, Stulting RD. Patientreported symptoms associated with graft reactions in high-risk patients in the collaborative corneal transplantation studies. Collaborative Corneal Transplantation Studies Research Group. Cornea. 1995;14(1):43-8.

6. Nishiwaki-Dantas MC, Dantas PEC, Holzchuh N, Lui Neto A, Giovedi Filho R, Giovedi M, Almeida GV. Indicações de transplante penetrante de córnea: 1991-1995. Arq Bras Oftalmol. 1998;61(1):26-33.

7. Chalita MRC, Diazgranados EBM, Sato EH, Branco BC, Freitas D. Rejeição corneana pós transplante de córnea: análise de dados do Banco de Olhos do Hospital São Paulo - Escola Paulista de Medicina. Arq Bras Oftalmol. 2000; 63(1):55-8

8. Pereira MLM, Passos MC, Santos AMC, Pecego JG. Normas médicas em Bancos de Olhos: controvérsias. Rev Bras Oftalmol. 2002;61(3):163-7.

9. Sobotkka Ventura AC, Rodokanak-von Schrenk A, Hollstein K, Hagenah M, Böhnke M, Engelmann K. Endothelial cell death in organ-cultured donor corneae: the influence of traumatic versus nontraumatic cause of death. Graefs Arch Clin Exp Ophthalmol. 1977;235(4):230-3.

10. Ghanem VC, Isaac DLC, Nascimento MA, Castro RS, Kara-José N. Eficácia na utilização de córneas no transplante penetrante. Arq Bras Oftalmol. 2003; 66(3):311-4.

11. Palay DA, Kangas TA, Stulting RD, Winchester K, Littof D, Krachmer JH The effects of donor age on the outcome of penetrating keratoplasty in adults. Ophthalmology. 1997;104(10):1576-9.

12. Redbrake C, Becker J, Salla S, Stollenwerk R, Reim M. The influence of the cause of death and age on human corneal metabolism. Invest Ophthalmol Vis Sci. 1995;36(2):3553-6. Comment in: Invest Ophthalmol Vis Sci. 1995; 36(2):259.

13. Hirai FE, Adán CBD, Sato EH. Fatores associados à qualidade da córnea doada pelo Banco de olhos do Hospital São Paulo. Arq Bras Oftalmol. 2009; 72(1):57-61.

14. Cornea Donor Study Investigator Group, gal RL, Dontchev M, Beck RW, Mannis MJ, Holland EJ, Kollman C, Dunn SP, et al. The effect of donor age on corneal transplantation outcome results of the cornea donor study. Ophthalmology.2008;115(4):620-626. e6.

15. Molina L, Souza RB. Estudo experimental do meio de McCarey-Kaufman. Rev Bras Oftalmol. 1992;51(1):43-9.

16. Wang SK, Gottsch JD, Green WR, Chen CH, Stark WJ. Corneal graft survival in the cat with prolonged preservation in MacCarey-Kaufman and KSol media. Arch Ophthalmol. 1988;106(7):981-5.

17. Bourne WM. Endothelial cell survival on transplanted human corneas preserved at $4 \mathrm{C}$ in $2.5 \%$ chondroitin sulfate for one to 13 days. Am J Ophthalmol. 1986;102(3):382-6

18. Belfort Júnior R. Ceratoplastia e ceratectomia. In: Belfort Júnior R, Kara José N, editores. Córnea. São Paulo: Rocca; 1996. p.493-504

19. Tanure MAG, Muinhos GK, Gonçalves IRF, Jacobovitz S, Moya STF, Lima WTM. Utilização de córneas de doadores com idade igual ou superior a 60 anos em ceratoplastias penetrantes. Rev Bras Oftalmol. 1997;56(12):963-70.

20. Urbano AP, Akaishi PMS, Sarmento S, Urbano AP, Costa VP, Arieta CL. Evolução das ceratoplastias penetrantes realizadas por residentes. Rev Bras Oftalmol. 2001;60(10):741-8.

21. Van Meter WS, Katz DG, White H, Gayheart R. Effect of death-to-preservation time on donor corneal epithelium. Trans Am Ophthalmol Soc. 2005; 103:209-22; discussion 222-4.

22. Hirai FE, Klatte S, Pacini KM, Sato EH. Falência primária pós-transplante de córnea em serviço universitário. Arq Bras Oftalmol. 2002;65(6):655-7.

23. Kervick GN, Shepherd WF. Changing indications for penetrating keratoplasty. Ophthalmic Surg. 1990;21(3):227.

24. Brasil. Ministério da Saúde. Portaria $\mathrm{n}^{\circ}$ 2600, de 21 de outubro de 2009. Aprova o Regulamento Técnico do Sistema Nacional de Transplantes [Internet]. [citado $2010 \mathrm{Fev}$ 20]. Disponível em: http://www.abto.org.br/download/Portaria2600_GM.pdf. 